\title{
Paradigmas sociológicos e categoria de gênero. Que renovação aporta a epistemologia do trabalho?
}

Helena Hirata - Socióloga, Diretora de Pesquisa no Centre Nationale de la Recherche Scientifique, Institut de Recherche sur les Sociétés Contemporaines-IRESCO, Groupe d'Etudes sur la Division Sociale et Sexuelle du Travail-GEDISST, Paris, França.

Danièle Kergoat - Socióloga, Diretora de Pesquisa no Centre Nationale de la Recherche Scientifique, Institut de Recherche sur les Sociétés Contemporaines-IRESCO, Groupe d'Etudes sur la Division Sociale et Sexuelle du Travail-GEDISST, Paris, França.

\section{Resumo}

A dimensão sexuada nas análises do trabalho está posta há cerca de trinta anos pela sociologia do trabalho francesa. Este artigo faz um balanço dessa integração conceitual e de aportes epistemológicas. Cabe inicialmente apresentar o estado da arte das rupturas conceituais e de sua periodização. Com efeito, as problemáticas que levam em conta as categorias de sexo tem uma história, que abriu a possibilidade de rupturas teóricas e epistemológicas maiores, notadamente com uma tradição da sociologia do trabalho francesa centrada sobre a figura arquétipica, universal, do operário da grande empresa industrial. O desafio teórico foi o de integrar as categorias de gênero no campo do trabalho retraduzindo métodos, enfoques, instituições constitutivas desta disciplina e instrumentos de trabalho.

Procuramos demonstrar, a partir de uma revisão da produção científica das últimas décadas, os aportes trazidos pelas pesquisas que introduziram a perspectiva de gênero na análise dos objetos tradicionais da sociologia do trabalho. Pontuaremos algumas diferenças de caráter nacional, - notadamente européias - entre as maneiras que têm as sociologias do trabalho de integrar a relação social de sexo.

\section{Palavras-chave}

Epistemologia, Gênero, Divisão Sexual do Trabalho, Sociologia do Trabalho.

\section{Abstract}

This article examines the conceptual integration and epistemological contributions made by gender analysis of work established thirty years ago, by the French sociology of work. Initially, the stateof-the-art and the time table of conceptual ruptures are presented. The history of problems related to gender classification led to increased theoretical and epistemological ruptures, particularly within the French tradition related to the sociology of work, focused on the archetypical image of large company workers. The theoretical challenge was to include gender categories in the work field, rethinking methods, focus, and constituent institutions related to this subject and to its working tools.

Through the review of the scientific production released in recent decades, this work presents the contributions made by researches introducing gender perspectives to the traditional object analysis of the sociology of work. Some national differences used by the sociology of work in order to integrate gender social relations are pointed out notably European ones, among others.

\section{Keywords}

Epistemology, Gender, Sexual Division of Labour, Sociology of Work. 


\section{INTRODUÇÃO}

A problemática da integração da dimensão sexuada nas análises do trabalho, na sociologia francesa, está posta aproximadamente há trinta anos. Se a sociologia do trabalho tomou parte do desafio teórico de incorporou as categorias de sexo à teoria social, esta integração resta dolorida e conflituosa na medida em que os paradigmas universalistas sempre dominantes no campo do trabalho, atravessaram os métodos, os enfoques, os instrumentos e as instituições constitutivas desta disciplina.

É sobre a história e o balanço dessa integração relativa que nós gostaríamos de nos deter aqui. Cabe inicialmente apresentar o estado da arte das rupturas conceituais e de sua periodização. Com efeito, as problemáticas que levaram em conta as categorias de sexo que abriram a possibilidade de rupturas teóricas e epistemológicas maiores, notadamente com uma tradição da sociologia do trabalho francesa centrada sobre a figura arquétipa do operário (masculino) da grande empresa industrial, figura considerada como universal. Estas rupturas têm consequências teóricas de várias naturezas:

1 O lugar real e o estado sexuação dos objetos da sociologia da trabalho;

2 O valor heurístico na análise do trabalho;

3 O seu papel na renovação dos paradigmas dominantes no campo do trabalho;

4 As construções alternativas atuais;

Esta comunicação mostrará, a partir de exemplos concretos, os aportes trazidos pelas pesquisas que introduziram uma perspectiva de gênero na análise dos objetos tradicionais da sociologia do trabalho. Pontuaremos algumas diferenças de caráter nacional - notadamente européias - entre as maneiras que têm as sociologias do trabalho de integrarem a relação social de sexo.

\section{A DUPLA RUPTURA: ENSAIO DE PERIODIZAÇÃO}

Desde a metade dos anos 1970, inúmeros trabalhos na França deram ao conceito de trabalho uma dimensão sexuada. No entanto, não se pode dizer que essa inclusão gozasse de alguma estabilidade na medida em que ela não significou a acesso a um real droit de cité na comunidade científica. Apesar do peso crescente das pesquisas sobre as mulheres e o trabalho na sociologia do trabalho francesa nestes últimos anos, «as figuras neutras 
do pobre, do precário, do vulnerável, são construídas em referência à figura masculina do assalariado com emprego a tempo integral e contrato com duração indeterminada.

As noções de vulnerabilidade, de desfiliação, e de flexibilidade da condição salarial são apresentadas de maneira neutra, mas representam o negativo da figura do assalariado masculino durante les trente glorieuses"1. Um balanço recente da situação da sociologia do trabalho indicou claramente os avanços e ao mesmo tempo as dificuldades persistentes para integrar a perspectiva de gênero. Lallement (2003) mostra como a produção de trabalhos originais nesse domínio foi progressivamente legitimada, sem deixar de observar que não é certeza que o gênero seja "completamente reconhecido e compreendido no meio acadêmico». ${ }^{2}$

Uma periodização mais fina permite identificar os momentos de inclusão desta perspectiva, inclusão que foi marcada por rupturas com os paradigmas dominantes; nos parece útil e necessário para aprofundar a análise das razões desta instabilidade. Tratar-se-á aqui de analisar dois tipos de rupturas induzidas pela introdução sucessiva das categorias de sexo, de relações sociais de sexo, ou de gênero. A dificuldade do ensaio de tal periodização vem do fato de que, si essas duas rupturas não são da mesma natureza, elas se recortam e se superpõem parcialmente no tempo.

\subsection{A introdução das categorias de sexo}

As primeiras rupturas com a tradição da sociologia do trabalho francesa pode ser situada nos anos cinquenta com os trabalhos pioneiros de Madeleine Guilbert et Viviane Isambert-Jamati (1956) sobre o trabalho à domicílio ${ }^{3}$. No início dos anos 1960, elas foram igualmente autoras do capítulo sobre «La répartition par sexe $»^{4}$ do Traité de Sociologie du Travail de G. Friedmann et P. Naville (1961). Pode mesmo ser considerado como um bom exemplo de que a emergência dos estudos sobre as mulheres

\footnotetext{
Cf. Nicole Gadrey, “L'enseignement 'sociologie des rapports sociaux de sexe et de genre”, in Le genre comme catégorie d'analyse, Fougeyrollas-Schwebel D., Planté C., Riot-Sarcey M., Zaidman C. (dir.), L'Harmattan, 2003, p. 33-38.

2 LALLEMENT M., « Quelques remarques à propos de la place du genre dans la sociologie du travail en France », in Le travail du genre. Les sciences sociales à l'épreuve des différences de sexe”, Laufer, J., Marry, C., Maruani, M. (dir.), Paris : La Découverte, 2003, p. 123-137.

3 GUILBERT M., ISAMBERT-JAMATI V., Travail féminin et travail à domicile, éd. du CNRS, 1956.

${ }^{4}$ GUILBERT M., ISAMBERT-JAMATI V. "La répartition par sexe", in Friedmann G. et Naville P., Traité de sociologie du travail, Armand Colin, 1961, pp. 266-282.
} 
enquanto um campo de conhecimento que alterará o enfoque tradicional da sociologia do trabalho francesa que exclui o trabalho doméstico do campo do trabalho. A questão é posta, mas assim mesmo em poucas linhas, e, curiosamente por sinal, em conclusão do capítulo sobre o desemprego, escrito por Jacques Dofny: «mas a sociologia do trabalho deve parar na análise da população ativa ? (...). A noção de mercado de trabalho é central nessas classificações. Esta definição restritiva do trabalho exclui uma substancial parte dos trabalhos efetuados na vida social, precisamente aqueles que não são objeto de uma remuneração, a exemplo dos trabalhos domésticos ou a participação ativa em diversas estruturas da sociedade sem fins lucrativos. O que é definido como trabalho, é toda atividade relevante da contabilidade nacional. Não é evidente que esse ponto de vista seja aquele do sociólogo, tradicionalmente atraído pelas análises da divisão do trabalho social. (...).” (p. 324)

A obra clássica de Madeleine Guilbert $(1966)^{5}$ consagrada ao trabalho profissional dos operários faz referência ao trabalho doméstico: ela mostrou que os postos de trabalho ocupados pelas mulheres na indústria tinham características próximas daquelas do trabalho doméstico (repetitividade das tarefas, minuciosidade, sequências curtas, tensão nervosa etc...). Mas ela não confere centralidade teórica à articulação entre trabalho doméstico e trabalho profissional.

Somente em 1971 que apareceria o artigo fundador de NicoleClaude Mathieu: Notes pour une définition sociologique des catégories desexe. não será a não ser muito mais tarde que pesquisadores dele se apropriariam. De fato, até meados dos anos 70 , os primeiros trabalhos começaram a introduzir uma oposição binária (grupo de homens ou grupo de mulheres) mas as categorias de sexo tinham uma única função de classificação. Paralelamente, os movimentos de mulheres fariam avançar o debate teórico sobre a noção de opressão; teorizavam sobre as relações entre os sexos mas isso não estava integrado às categorias. ${ }^{7}$

\footnotetext{
${ }^{5}$ GUILBERT M. (1966) Les fonctions des femmes dans l'industrie. La Haye : Mouton.

${ }^{6}$ Cet article est paru initialement dans Epistémologie sociologique, ${ }^{\circ} 11,1^{\text {er }}$ semestre 1971, pp. 1939. Il est réédité dans L'Anatomie politique (Paris: Côté-femmes, 1991). Il s'agissait initialement d'une communication au VIIème Congrès mondial de sociologie, septembre 1970.

${ }^{7}$... et les sociologues qui intégraient cette notion (C. Delphy, C. Guillaumin, N.C. Mathieu...) étaient perçues comme des "militantes" dont les travaux n'avaient pas droit de cité dans la sphère académique.
} 
Tratava-se, portanto, nesse período, de estudar o trabalho de mulberes, mais que o trabalho segundo os sexos; de estudar notadamenbte o trabalho profissional e assalariado, mais que o trabalho doméstico enquanto trabalho ou a articulação trabalho e família.

Foi ao longo dos anos 1970 e 1980 que se estruturou progressivamente na França uma orientação de pesquisa sobre «a transformação do estudo das mulheres em estudo « dos sexos » e, simultaneamente, a interpenetração dos domínios antes separados da sociologia do trabalho e da sociologia da família » (N.C. Mathieu, 1991, p. 28).

Os trabalhos se multiplicaram na medida em que os grupos de reflexão confrontaram, em particular, os dados produzidos no âmbito da sociologia do trabalho e da sociologia da família. Uma obra coletiva é lançada Le sexe du travail. Structures familiales et système productif $(1984)^{8}$ cujo título indica bem a extensão dada ao conceito de trabalho de um lado (a definição de «trabalho» não é mais comandada pelas categorias econômicas, o trabalho doméstico tal qual ele foi modalizado por inúmeros estudos, tem seu lugar pleno e inteiro) e, de outro lado, a vontade de pensar a articulação entre esferas da produção e da reprodução.

\subsection{Introdução teórica do conceito de relações sociais de sexo}

Seria falso dizer que nesses trabalhos a categoria de sexo não seria mais que uma variável de classificação. A noção de hierarquia entre os sexos estava ai, por exemplo, onipresente. Mas, as categorias não formavam um sistema e seria apenas progressivamente que se imporia a necessidade de reconhecer e de conceitualizar a relação social que uniria essas categorias. É o que os franceses chamaram «relações sociais de sexo»? Desde meados dos anos 1980, numerosos trabalhos, individuais e coletivos, consagraram-se ao tema ${ }^{10}$. Nessa perspectiva, em 1987, foi organizada em Paris, o Seminário Internacional intitulado As relaçôes sociais desexo:problemática, metodologiase campos de análise.

\footnotetext{
${ }^{8}$ Presses Universitaires de Grenoble, 1984

9 L'émergence de cette notion correspond grosso modo à celle de "gender" dans les pays anglophones. La préférence pour l'un ou l'autre terme ne peut, faute de place, être explicitée ici. ${ }^{10}$ A titre d'exemple, cf.: DEVREUX A.M.,DAUNE-RICHARD A.M.: "La construction sociale des catégories de sexe", in Sexe et catégories, Université de Provence : BIEF n¹7, p. 39-53, déc. 85; BATTAGLIOLA F., COMBES D., DEVREUX A.M., FERRAND M., LANGEVIN A.: A propos des rapports sociaux de sexe: parcours épistémologiques (1986) Paris : CSU-IRESCO.
} 
Esta relação social é caracterizada como transversal ao conjunto do sistema social, e por isso historicizável (ela se reproduz mas conhece as mudanças constantes), é uma relação de poder, de dominação; cada categoria não existe a não ser em relação a outra, elas se co-constróem incessantemente. Essa conceitualização permitia descolar os grupos sociais, homens e mulheres, da bicategorização biologizante machos e fêmeas.

Enfim, se nós definimos a relação social como uma tensão que atravessa o campo social, tensão que erige certos fenômenos sociais em jogo em torno dos quais se constituem grupos com interesses antagônicos, chegar-se à proposição seguinte: a divisão sexual do trabalho tem o status $d^{\prime}$ enjeu das relações sociais de $\operatorname{sexo}^{11}$. Nós temos desde então um paradigma sólido para incluir a diferença dos sexos na sociologia do trabalho.

\section{APORTES DE PESQUISA E SOCIOLOGIA DO TRABALHO}

Os exemplos são hoje numerosos: o emprego e o desemprego, as qualificações e a competência, as técnicas e a inovação, a organização do trabalho e as situações de trabalho, os novos modelos produtivos e a especialização flexível, a questão das obrigações e do controle social, as trajetórias profissionais e as carreiras, os novos movimentos sociais dos assalariados, as novas formas de migração Sud/Nord, entre outros, foram objeto de numerosos trabalhos integrando a dimensão de sexo. Das nossas próprias pesquisas tratando desse domínio, nós nos limitamos aqui a apresentar três exemplos:

\subsection{O conceito de trabalho}

Os fundadores da sociologia do trabalho partem de um modelo asexuado, seu sujeito - o homem - tendo sido erigido como universal. Esse modelo foi fortemente interpelado desde os anos 70 pela problemática da divisão sexual do trabalho (1): trata-se de ir na direção de uma reconceituação do travail pela inclusão desse conceito; 1) do sexo social (do gênero); 2) do trabalho doméstico. E acabou sendo ampliada para o entendimento do trabalho não assalariado, não remunerado, não

\footnotetext{
${ }^{11}$ KERGOAT D. "Division sexuelle du travail et rapports sociaux de sexe" in Dictionnaire critique du féminisme, Hirata H., Laborie F., Le Doaré H., Senotier D. (coord.), PUF, 1 ère éd: 2000, pp. 35-44.
} 
mercantil, do trabalho informal. Trabalho profissional e doméstico, produção e reprodução, regime salarial e família, classe social e sexo social, são consideradas como as categorias indissociáveis. A partir desta proposição epistemológica e de imbricação de dimensões antes separadas, foi possível construir um questionamento permitindo jogar luz entre as diferentes esferas de atividade (2) e de romper definitivamente com a antiga noção de especificidade".

Ao introduzir-se a relação social (de sexo) na análise da atividade do trabalho, outros desdobramentos teóricos se tornaram possíveis. Mencionamos em particular: a análise de um certo número de empregos majoritariamente femininos em termos de "relações de serviço", que se apoiaram sobre as conceitualizações anteriores do trabalho doméstico (3).

\subsection{A qualificação}

Não é de surpeender que o conceito de qualificação, enquanto uma noção-chave em sociologia do trabalho, tenha sido um dos primeiros a ser confrontado à análise crítica impulsionada por esta sociologia. Bastaria, na realidade, passar em revista as sifras produzidas pelas pesquisas quantitativas sobre emprego, por exemplo, os dados da primeira pesquisa sobre as condições de trabalho (outubro de 1978) para que aparecesse fortemente uma primeira situação: nos anos 80 (4), as mulheres operárias estavam massivamente localizadas em estratos mais baixos de qualificação: elas eram operárias não qualificadas ou generalistas ( $78 \%$ dentre elas) enquanto que os homens estavam majoritariamente operários qualificados (55\%). As condições de trabalho seguiam esta hierarquia: mais frequentemente que os operários, as operárias trabalhavam na linha de montagem, estavam submetidas a maiores constrangimentos de tempos e movimentos, com interdições mesmo para o uso da palavra (5). Encontra-se assim, a situaçõe descrita por Madeleine Guilbert. Estamos diante do primeiro nível da divisão sexual do trabalho: o da categorização social pelo sexo.

Mas existe ainda um segundo: os levantamentos do Ministério do Trabalho, na França, que ao destacar cruzamentos entre sexo e qualificação fazem aparecer que as determinações correntemente admitidas e generalizadas ao conjunto da mão de obra recobrem realidades bem diferentes segundo o sexo do trabalhador em questão. Este crescimento permite comparar as condições de trabalho de operários e operárias qualificados e não qualificados, ou qualificadas. Ele tem colocado em 
evidência fatos surpreendentes para a doxa clássica: uma operária qualificada tendo estatisticamente mais chances que um operário não qualificado para trabalhar na esteira de montagem, de fazer um trabalho repetitivo e de não ter o direito se exprimir (5).

Tais resultados certamente questionaram os acquis sociológicos anteriores sobre a qualificação uma vez que mostravam que existe bem uma divisão social do trabalho por sexo, que se entrecruza com as outras formas de divisões sociais mas que não são redutíveis a elas, a uma simples diferença quantitativa entre os atributos dos trabalhadores concernidos (por exemplo, no nível da formação). E como il est acquis que todas as outras formas de divisão social do trabalho referenciam à relações de poder, era legítimo de se concluir pela existência de uma relação social: a relação de sexo (ou de gênero).

Atualmente, é mais frequente usando o termo "competência" que "qualificação", quando a sociologia é confrontada no campo temático da empresa. Esta noção coloca certos problemas, nós não retomaremos mais aqui o debate sobre a qualificação/competência: todos os leitores já o conhecem. Nós diremos simplesmente que o modelo de competência, no que se refere às mudanças para o ou a salariado, a (individualização face à hierarquia e ao coletivo de trabalho, exigências de savoir-être, de implicações no trabalho...), se joga e é jogado de maneira diferente, senão por vezses oposta no caso dos homens e também das mulheres (7). Divisão sexual do trabalho e relações de gênero se reproduzem a não ser que tardem a se colocar coletivos que sofrem de novas políticas de mão de obra. Em todo caso esses dois conceitos são preciosos para se compreender, na sua complexidade, tanto a competência (8) quanto a qualificação.

\subsection{Novos Modelos produtivos e especialização "flexível”}

As alternativas aos modelos produtivos tayloristas ou fordistas, designados, segundo as autoras por "especialização flexível, "novo conceito de produção, "neo-taylorismo" ou ainda "pos-fordismo", são raramente conjugados ao feminino. Esses termos se pretendem neutros, mas na realidade eles generalizam ao conjunto da mão de obra as transformações no universo produtivo que concerne essencialmente aos homens. Assim, a tese da requalificação dos operadores seguida de inovações tecnológicas e organizacionais é fortemente interpelada por uma análise em termos da divisão sexual e internacional do trabalho (9). ... hommes des pays du Nord. 
Este movimento de requalificação toca essencialmente a uma parte de trabalhadores. Suas conseqüências sobre a mão de obra feminina são muito mais contraditórias, a evolução do debate teórico atesta: a relação entre especialização flexível e negação da qualificação feminina, desenvolvida por Jane Jenson (10), a tese da justaposição entre taylorismo e additiité de tâxhes (ao feminino) e requalificação (ao masculino), de Danièle Kergoat (11), e enfim, mais recentemente, a idéia da "flexibilité assistida pelo computador", de Sophie Prunier (12).

Estes modelos iluminam os resultados de pesquisa empíricas (sendo muitas vezes por estes interrogados). Uma enquete realizada recentemente em firmas multinacionais francesas no Brasil (13) mostrou três modalidades de organização do trabalho operário distintas. Numa empresa de biscuits, flexibilidade e trabalho em equipe dos efetivos masculinos, linhas de embalagens com cadência e ritmos impostos para as mulheres operárias. Em uma empresa de fabricação de para-brisas, havia sido implantado a inversão do esquema da divisão sexual do trabalho: um gheto feminino, enclave sob a forma de salle blanche, com exigências de dextérite manual, rigor e higiene, e postes masculinos sob cadencia imposta pelas máquinas (saída de para-brisa ao forno). Entretanto, uma organização flexível estava em curso de implantação, os homens eram os únicos a serem beneficiados de uma política ativa de formação. Enfim, numa empresa farmacêutica, o grupo de mulheres foi tocada também pelo movimento de requalificação, participando das inovações organizacionais. Homens e mulheres tinham acesso à formação, a clivagem se situando entre postes de execução (operadoras de máquina) e os postes mais técnicos de enquadramento (chefes e engenheiros).

Esses exemplos atualizam plenamente a interrogação de Jane Jenson: "será que as mulheres e os homens beneficiam-se igualmente dos processos de requalificação do trabalho e dos novos pesos conferidos ao trabalho qualificado? (14) Colocar esta questão permite, entretanto, de ver como, caso a caso, a organização do trabalho utiliza a divisão sexual do trabalho como um motor poderoso para remodelar novas formas.

\section{DIFERENÇAS NACIONAIS NA INTRODUÇÃO DO GÊNERO E NA CONSIDERAÇÃO DA CENTRALIDADE DO TRABALHO}

Pode-se constatar que a introdução das categorias de sexo e de relações sociais de sexo no âmago da análise das relações de trabalho, salariado e doméstico, pode contribuir tanto com os conhecimentos 
renovados sobre o trabalho, quanto à formulação de novas interrogações e à abertura de outros campos de pesquisa. No entanto, esse movimento não se fez da mesma maneira, não seguiu nem os mesmos ritmos, nem as mesmas linhas de força, nos diferentes contextos nacionais, notadamente europeus.

Uma primeira grande crivagem se situa entre os países anglo-saxões e os países francofones. Para estes últimos, pode-se situar nos anos 1980 a re-interrogação sistemática dos instrumentos e dos métodos correntemente utilizados no domínio do trabalho ${ }^{12}$.

Simultaneamente, nos países anglo-saxões estava posta a questão da elaboração de uma epistemologia ou de epistemologias feministas que interrogavam a natureza da objetividade, o acesso sexuado ao conhecimento, a relação entre o objeto e o sujeito da pesquisa, a construção social - e sexuada - da natureza, da verdade e da cultura. ${ }^{13}$ Na França se observarmos que desde o final dos anos 70 há um movimento de sexuação da sociologia do trabalho, não houve no entanto a constituição de uma epistemologia feminista como nos Estados Unidos, esta última permanecendo por sinal pouco conhecida; na França, pensava-se que a concepção tradicional de objetividade e o postulado da neutralidade sociológica mereceriam de ser rediscutidas ${ }^{14}$ ?

Nós queremos, enfim, para concluir, sublinhar algumas das diferenças e convergências entre as sociologias nacionais do trabalho, de uma parte, e algumas especificidades da sociologia do trabalho francesa, de outra.

Uma primeira convergência pode ser percebida na emergência sucessiva das «mulheres », primeiro, «dos sexos » e-ou do « gênero », em seguida, nas sociologias nacionais, qual que seja seu desdobramento no tempo ou no momento onde se situa sua aparição ${ }^{15}$.

Uma segunda convergência concerne a esse momento de emergência das "mulheres" ou das "ategorias de sexo" na sociologia do trabalho: a

${ }^{12}$ VANDELAC L., “...Et si le travail tombait enceinte ? Essai féministe sur le concept de travail”, Sociologies et sociétés, vol. XIII, n² 2, octobre 1981, p. 67-82.

${ }^{13}$ HARDING S. (ed. by) Feminism and Methodology, Indiana/Milton Keynes, Indiana University Press/Open University Press, 1987; Harding, S., Whose Science? Whose Knowledge?Thinking from Women's Lives. Ithaca, New York, Cornell University Press, 1991. HARAWAY, D.J., Simians, Cyborgs and Women. The Reinvention of Nature. New York, Routledge, 1991.

${ }^{14}$ Cf. GAUSSOT L., "La problématique des rapports sociaux de sexe : un devoir d'inventaire". Communication présentée au $1^{\text {er }}$ Congrès de l'AFS, Villetaneuse, février 2004.

${ }^{15}$ Voir, pour la sociologie du travail anglo-saxonne, WACJMAN J., "Le genre au travail", in Le travail du genre, op. cit., p. 151-162. 
força dos movimentos feministas do final dos anos 1960 e início dos anos 1970 nos países capitalistas desenvolvidos foi determinante e precediu a análise tomando em consideração as mulheres-as categorias de sexo. Nos países semi-industrializados ditos «em vias de desenvolvimento», se fez um pouco mais tarde, e se pode periodizar esta aparição mais ou menos em 1975, no momento dos dez anos para as mulheres da Organização das Nações Unidas no México, acontecimento institucional a partir do qual se desenvolvem múltiplos grupos feministas na América Latina.

Uma terceira convergência está ligada à anterioridade da antropologia em relação à sociologia quanto à introdução de um enfoque homens-mulheres na divisão social do trabalho (cf. notadamente Kate Young no Royaume-Uni, N.C. Mathieu na France e, bem anteriormente, Margaret Mead aux Etats-Unis).

Uma quarta convergência é a quase total impermeabilidade das sociologias do trabalho às pesquisas sobre o gênero da filosofia queer (Judith Butler ${ }^{16}$ ), e da psicanálise feminista (Nancy Chodorow ${ }^{17}$ ). Para a França, esta característica é provavelmente ligada à estrita demarcação observável até ao início do anos 1980 na sub-diciplina que se localizava entre família e trabalho, e àquela entre sexualidade, corpo e profissionalidade que foi mantida através o tempo. E se existe uma corrente da sociologia do trabalho francesa trabalhada pela psicanálise (Eugène Enriquez, Vincent de Gaulejac), ela não leva em conta a perspectiva psicanalítica feminista.

Quanto às diferenças, a primeira observação concerne também a relação entre as disciplinas: a influência e as aproximações disciplinares desenham contornos específicos em cada sociologia nacional do trabalho. Assim, a influência - recíproca - entre uma sociologia das relações sociais (de sexo) e a psicopatologia ou psicodinâmica do trabalho (C. Dejours) parece muito específica ao caso francês, onde ela se afirmou desde os anos 1980; no caso da sociologia do trabalho anglo-saxona, a sociologia da cultura e a gestão pareciam ter uma influência muito mais decisiva quanto às configurações temáticas ${ }^{18}$.

\footnotetext{
${ }^{16}$ BUTLER J., Gender Trouble. Feminism and Subversion of Identity, New York/London, Routledge, 1999 (1990)

${ }^{17}$ CHODOROW N., The Reproduction of Mothering. Psychoanalysis and the Sociology of Gender, Berkeley, Los Angeles, London, University of California Press, 1999 (1978)

${ }^{18}$ Cf. WACJMAN J., op. cit.
} 
Mas é sem dúvida à propósito do trabalho e de sua centralidade que as diferenças são as mais marcantes. Com efeito, o debate centralizado do trabalho-fim do trabalho, em ligação com a análise da centralidade diferencial do trabalho para as mulheres e para os homens, é praticamente inexistente fora do quadro francês. Praticamente inexistente também, a afirmação do lugar central do trabalho na sociedade, a partir de uma definição ampla do trabalho integrando o trabalho não-remunerado, o trabalho doméstico, o trabalho informal, etc.. em oposição à tese do « fim do trabalho ».

Sem dúvida a explicação dessas diferenças (influência da gestão no debate da sociologia do trabalho anglo-saxona, e do lugar do debate sobre a centralidade do trabalho na França) deve-se procurar na gênese das duas sub-disciplinas (nós pensamos por exemplos nos estudos fundadores realizados pela Western Electric Company nos anos 1930 nos Estados-Unidos ${ }^{19}$ ).

\section{CONCLUSÃO}

Nós mostramos como a introdução das categorias de sexo e depois as relações sociais de sexo na sociologia do trabalho renovaram os conceitos e os enfoques sociológicos. Quanto à inovação da epistemologia do trabalho, nós vimos como o balanço é diversificado.

A crítica-descontrução do conceitos clássico do trabalho conduziu certamente à elaboração de um paradigma sólido - o da teoria da divisão sexual do trabalho, profissional e doméstica, como campo de relações sociais de sexo - , e alternativo aos paradigmas clássicos gender blinded existentes para repensar as categorias, os métodos e as problemáticas da sociologia do trabalho. Mas, se o acúmulo de dados e de trabalhos foi importante nestes últimos vinte anos, muito resta ainda a fazer. Os aspectos institucionais se arvoram cada vez mais significativos, enquanto blocagens, mas talvez poderiam eles um dia se constituir em leviers?, na diversificação e no alargamento do domínio de pesquisa sobre o «sexo do trabalho ».

\footnotetext{
${ }^{19}$ DESMAREZ P., La sociologie industrielle aux Etats-Unis, Armand Colin, 1986.
} 